Methods Patients from two well-defined multiethnic and multicenter lupus cohorts, one from the US and the other from Latin America were included. SLE was defined in the US cohort using the 1982/1997 ACR criteria and as diagnosed by the physician for the Latin American cohort although more than $95 \%$ of these patients also achieved the 1982/1997 ACR criteria. For these analyses the 1982/1997 ACR criteria were used as the gold standard. Demographics and disease activity at baseline were compared in order to determine differences between those patients who achieved the EULAR/ACR criteria before, at the same time or after than 1982/1997 ACR criteria.

Results Five-hundred and fifty-eight patients out of 640 from the US cohort and 956 out of 1047 from the Latin American cohort achieved the EULAR/ACR criteria. The sensitivity of the EULAR/ACR criteria in the US cohort was $87.2 \%$ and in the Latin American cohort was 91.3\%; in the US cohort, 41 (7.3\%) achieved the EULAR/ACR criteria earlier, 344 (61.6\%) at the same time and $173(31.0 \%)$ later than the ACR criteria; for the Latin American cohort these numbers and percentages were 71 (7.4\%), $556(58.2 \%)$ and 329 (34.4\%), respectively. Patients who achieved the EULAR/ACR criteria earlier were less likely to be Caucasian; disease activity (measured with the SLAM: systemic lupus activity measure for the US cohort, and with the SLEDAI: Systemic Lupus Erythematosus Disease Activity Index for the Latin American cohort) did not differ between the groups. These data are depicted in table 1.

Conclusions The sensitivity of the 2018 EULAR/ACR criteria against the 1982/1997 ACR criteria (gold standard) was high $(87.2 \%$ for the USA and $91.3 \%$ for the Latin American cohort). While the large majority of patients were classified at the same time $(58.2 \%$ to $61.6 \%)$ with both criteria, about one third were classified later and a small proportion (about 7\%) were classified earlier with the 2018 EULAR/ACR criteria. Further examination of the 2018 EULAR/ACR criteria is warranted.

Funding Source(s): None

\section{COMPARATIVE STUDY IN SLE PATIENTS WITH AND WITHOUT RENAL INVOLVEMENT BY LABEL FREE PROTEOMIC ANALYSIS OF URINE}

${ }^{1}$ Esther Ruiz*, ${ }^{1}$ Natalia Rivera, ${ }^{1} \mathrm{M}$ Luz García, ${ }^{1} E v a$ Galindez, ${ }^{1}$ Ana Intxaurbe, ${ }^{1} J u a n$ Blanco, 'Olaia Fernández, ${ }^{1}$ Iñaki Torre, ${ }^{1}$ Clara Pérez, ${ }^{1}$ Itziar Calvo, ${ }^{1}$ Oihane Ibargengoitia, ${ }^{1}$ David Monterom, 'Lucia Vega, ${ }^{1} \mathrm{M}$ Jesús Allande, 'Helena Ugarte, 'Unai Aresti, ${ }^{2}$ Mikel Azkargorta, ${ }^{2} F e ́ l i x$ Elortza. 'Osi Bilbao-Basurto; ${ }^{2} C I C$ bioGUNE, CIBERehd, ProteoRed-ISCIII

10.1136/lupus-2019-Ism.84
Background Lupus nephropathy (LN) is an important cause of morbidity and mortality in patients with Systemic Lupus Erythematosus (SLE). Considering that renal biopsy is a specialized technique and not risk free, a proteomics study is proposed to determine biomarkers that may help us to differentiate patients diagnosed with SLE with and without renal involvement.

Methods We selected 12 patients with SLE and renal involvement and 14 patients with SLE without renal involvement. There were no differences between groups according to race, gender and age. The patients were classified as moderate $(<500)$, mild $(150-500)$ or normal $(<150)$ level of proteinuria in the urine. A 24 hour urine sample was obtained for analysis. Proteomic analysis was conducted by label free nLC MS/ MS analysis.

Results The Principal Component Analysis (PCA) revealed differences between samples from patients who have high level of proteinuria in 24 hours and patients who do not have renal involvement. Interestingly, patients with mild proteinuria correlated better with patients without renal involvement than with the severe proteinuria group. A total of 292 proteins (identified with at least two peptides with a FDR $<1 \%$ ) were quantified and further considered in the analysis. Consistent with the nature of the sample, the Gene Ontology (GO analysis) of the whole list of identified proteins revealed the presence of extracellular (277 proteins, $\mathrm{p}=2.25 \mathrm{E}-171)$ and secretion-related proteins (49 proteins, $\mathrm{p}=1.1 \mathrm{E}-09$ ), among others. Proteins related to defensive processes were prominent among them.

Interestingly, clear differences were detected between the three subgroups of samples. The Students T-test analysis reflected the differential presence of 147 proteins $(p<0.01)$ between patients with and without renal involvement, being 17 more abundant in the urine of the patients with renal damage, whereas 130 showed the opposite pattern. The subset of proteins whose abundance increases upon renal damage is comprised of typical highly-abundant serum proteins. In addition, differences between most closely related groups (mild proteinuria and no renal affectation) revealed differences that may be useful for a better stratification of patients.

Conclusions A different protein pattern is observed between the groups of patients, so in a more detailed study we may indicate if some of these can serve as prognostic markers for this type of patients.

Funding Source(s): No funding 
Abstract 84 Table 1

\begin{tabular}{|c|c|c|c|c|c|}
\hline Status & Accession & $\begin{array}{l}\text { Un. } \\
\text { Pepts }\end{array}$ & Score & $\begin{array}{c}\text { Anova } \\
\text { (p) }\end{array}$ & Ratio \\
\hline \multirow{16}{*}{$\begin{array}{c}\text { Down upon } \\
\text { damage }\end{array}$} & KLK1_HUMAN & 2 & 105.38 & 2.37E-09 & 0.07 \\
\hline & CBPM_HUMAN & 4 & 144.09 & $2.27 \mathrm{E}-08$ & 0.10 \\
\hline & PVR_HUMAN & 3 & 178.14 & 3.30E-08 & 0.15 \\
\hline & MASP2_HUMAN & 3 & 213.26 & 5.71E-08 & 0.10 \\
\hline & KNG1_HUMAN & 18 & 1100.55 & $7.86 \mathrm{E}-08$ & 0.16 \\
\hline & BT2A1_HUMAN & 2 & 96.76 & $1.88 \mathrm{E}-07$ & 0.16 \\
\hline & I18BP_HUMAN & 3 & 118.31 & $5.71 \mathrm{E}-07$ & 0.08 \\
\hline & AMYP_HUMAN & 2 & 650.58 & 6.01E-07 & 0.10 \\
\hline & AMY1_HUMAN & 2 & 628.48 & 6.01E-07 & 0.10 \\
\hline & VMO1_HUMAN & 4 & 342.57 & $6.68 \mathrm{E}-07$ & 0.21 \\
\hline & VASN_HUMAN & 6 & 498.27 & $9.25 \mathrm{E}-07$ & 0.19 \\
\hline & APOD_HUMAN & 7 & 403.15 & 1.06E-06 & 0.24 \\
\hline & CADM4_HUMAN & 4 & 271.26 & $1.42 \mathrm{E}-06$ & 0.21 \\
\hline & SHSA5_HUMAN & 2 & 62.75 & $1.81 \mathrm{E}-06$ & 0.15 \\
\hline & CNTFR_HUMAN & 3 & 115.39 & 1.96E-06 & 0.05 \\
\hline & LRP2_HUMAN & 13 & 798.35 & $2.19 \mathrm{E}-06$ & 0.23 \\
\hline \multirow{16}{*}{$\begin{array}{l}\text { UP upon } \\
\text { damage }\end{array}$} & CYTC_HUMAN & 3 & 232.73 & $1.9 \mathrm{E}-03$ & 1.42 \\
\hline & THBG_HUMAN & 8 & 571.1 & $8.2 \mathrm{E}-03$ & 2.47 \\
\hline & A2GL_HUMAN & 10 & 801.87 & $3.3 \mathrm{E}-03$ & 2.69 \\
\hline & CNDP1_HUMAN & 2 & 150.97 & $8.1 \mathrm{E}-03$ & 3.41 \\
\hline & CBG_HUMAN & 7 & 492.53 & $4.2 \mathrm{E}-03$ & 3.69 \\
\hline & HPT_HUMAN & 18 & 1236.53 & $5.3 \mathrm{E}-03$ & 3.76 \\
\hline & CFAB_HUMAN & 2 & 155.83 & 2.0E-04 & 4.46 \\
\hline & TRFE_HUMAN & 42 & 3539.5 & 7.5E-04 & 4.67 \\
\hline & ALBU_HUMAN & 70 & 6073.45 & $2.3 \mathrm{E}-10$ & 6.29 \\
\hline & A1AG2_HUMAN & 8 & 834.2 & $1.3 \mathrm{E}-05$ & 6.76 \\
\hline & A1AG1_HUMAN & 10 & 996.35 & $1.3 \mathrm{E}-05$ & 6.88 \\
\hline & AFAM_HUMAN & 13 & 1120.44 & $1.2 \mathrm{E}-06$ & 8.01 \\
\hline & A1AT_HUMAN & 20 & 1493.01 & $3.6 \mathrm{E}-05$ & 12.06 \\
\hline & CO3_HUMAN & 9 & 693.16 & $6.8 \mathrm{E}-03$ & 12.43 \\
\hline & A1BG_HUMAN & 13 & 950.86 & $2.3 \mathrm{E}-04$ & 15.19 \\
\hline & CFAD_HUMAN & 4 & 224.79 & 9.7E-03 & 137.49 \\
\hline
\end{tabular}

Representative deregulated proteins in case of renal damage. Adhesion: Uniprot Adhesion. United Nations. Pepts.: Unique peptides. Score: Score by mascot. Test T (p): $\mathrm{p}$ value for the T test used for the differential analysis. Relationship: Relationship between the abundances of proteins calculated in the samples of patients with renal involvement/samples without renal involvement.

85 POLYAUTOIMMUNITY IN SYSTEMIC LUPUS ERYTHEMATOSUS. DATA FROM A LARGE SPANISH COHORT: SPANISH SOCIETY OF RHEUMATOLOGY REGISTRY OF PATIENTS WITH SYSTEMIC LUPUS ERYTHEMATOSUS (RELESSER)

${ }^{1}$ Natalia Mena-Vázquez*, ${ }^{1}$ Antonio Fernandez Nebro, ${ }^{2}$ Iñigo Rúa-Figueroa, ${ }^{3}$ Maria Galindo Izquierdo, ${ }^{4}$ Juan Ovalles-Bonilla, ${ }^{5}$ Alejandro Olivé-Marqués, ${ }^{6}$ Jaime Calvo, ${ }^{7}$ Javier Narváez-García, ${ }^{8}$ Eva Tomero Muriel, ${ }^{9}$ Esther Uriarte Isacelayam, ${ }^{10}$ Alina Boteanu, ${ }^{11}$ Mariano Andrés, ${ }^{12}$ Mercedes Freire González, ${ }^{13}$ Javier Narváez-García, ${ }^{14}$ Tomas $R$ Vazquez Rodriguez, ${ }^{15}$ Ricardo Blanco, ${ }^{16}$ José A Hernández-Beriaín, ${ }^{17}$ Jesus Ibañez,
${ }^{18}$ Enrique Raya, ${ }^{19}$ Jose Maria Pego Reigosa. ${ }^{1}$ UGC de Reumatología, Instituto de Investigación Biomédica de Málaga (IBIMA) Hospital Regional Universitario de Málaga, Spain; ${ }^{2}$ Department of Rheumatology, Dr Negrín General University Hospital, Las Palmas de Gran Canaria; ${ }^{3}$ Hospital Universitario 12 De Octubre; ${ }^{4}$ Hospital General Universitario Gregorio Marañón; ${ }^{5}$ Hospital German Trias i Pujol; ${ }^{6}$ Hospital Universitario Araba; ${ }^{7}$ Hospital de Bellvitge; ${ }^{8}$ Hospital De La Princesa; ${ }^{9}$ Hospital De Donostia; ${ }^{10}$ Hospital Ramón y Cajal; ${ }^{11}$ Hospital General Universitario Alicante; ${ }^{12}$ Hospital Juan Canalejo A Coruña (CHUAC); ${ }^{13}$ Bellvitge University Hospital, Barcelona; ${ }^{14}$ Hospital Universitario Lucus Augusti; ${ }^{15} \mathrm{H}$. Marque de Valdecilla; ${ }^{16}$ Hospital Insular De Gran Canaria; ${ }^{17}$ Clinica Povisa; ${ }^{18}$ San Cecilio Hospital, Granada (Spain); ${ }^{19}$ Complexo hospitalario Universitario Vigo

10.1136/lupus-2019-Ism.85 